\title{
Characterization of In-Plane Mechanical Properties of Laminated Hybrid Composites
}

\author{
K. G. Satish ${ }^{1 *}$, B. Siddeswarappa ${ }^{2}$, K. Mohamed Kaleemulla ${ }^{2}$ \\ ${ }^{1}$ Department of Mechanical Engineering, University B.D.T. College of Engineering, Davangere \\ 577004, India \\ ${ }^{2}$ Department of Industrial and Production Engineering, University B.D.T. College of \\ Engineering, Davangere 577004, India \\ *Corresponding Author: kgsati@gmail.com
}

\begin{abstract}
An experimental investigation was conducted to study the effect of hybrid composite specimen subjected to in-plane tensile and compressive loading. The laminated specimens in accordance with ASTM standards were fabricated using steel and nylon bi-directional mesh as reinforcements and polyester as the binder. The various volume fractions and fiber orientations were used in which the percentage of polyester (40\%) was maintained constant. From the investigations it is revealed that, the specimens with higher percentage of steel sustain greater loads \& also the strengths are superior in case of $0 / 90^{\circ}$ oriented specimens. A relationship between the tensile/compressive strength, fiber content and orientation has been established.
\end{abstract}

Keywords: Hybrid composite, In-plane loading, Polyester resin, Bi-directional Fibers.

\section{INTRODUCTION}

Fiber reinforced composites are certainly one of the oldest and most widely used composite materials. Their study and development have largely carried out due to their vast structural potential and also the concept and technology of fiber reinforced polymer composites have undergone a sea change with better understanding of the basics like the bonding mechanism between the matrix and fiber reinforcement, fiber orientation, fiber reinforcement size and distribution, morphological features etc. Fiber reinforced polymer composites have steadily gained applications in the fields ranging from aerospace to piping to sports equipment. This appeal is due primarily to their high strength-to-weight ratio, tailorable mechanical properties and fatigue resistance. 
In order to improve the properties of existing composites, a newer trend is towards the development of Hybrid Composites. Generally Hybrid applies to advanced composites and refers to use of various combinations of fibers or particulate in either thermoset or thermoplastic matrices. Hybrids have unique feature that can be used to meet the diverse and competing design requirements in a more cost effective way than either advanced or conventional composites.

Metal Fiber reinforced laminated composites are a new type of laminated composites, consisting of thin metal fibers with glass, carbon or Kevlar fibers with polymer matrix. They combine both the good characteristics of metals such as ductility, impact and damage tolerances with the benefits of fiber composite materials such as high specific strength, high specific stiffness and good corrosion and fatigue resistance. The bond lines act as barriers against corrosion and the laminate has an inherent high burn-through resistance as well as good damping and insulation properties. They can be a good choice for main aircraft structures, for example in lower and upper wings as well as in the fuselage and tail sections [1]. However, the components fabricated in polymeric composites present tight requirements in service and they can suffer mechanical damages during the utilization. The damages can occur during the fabrication process, handling, transportation, storage and maintenance [2, 3]. Recently, a new composite material has been developed to overcome this shortcoming. The steel reinforced polymer (SRP) consists of highcarbon steel unidirectional Hardwire fabrics embedded in polymer matrix [4].

Polymeric composites are susceptible to mechanical damages when they are subjected to efforts of compression, tension and flexural, which can lead to interlayer delamination. In any cases, the increase of the external load favors the propagation of delamination through the interlayer leading to the catastrophic failure of the component [5]. The tension and compression tests require only simple specimens, are easy to perform and give accurate and reliable measurements. For these reasons, they are attractive tests to determine as much of the mechanical properties of composite materials as possible. In a tensile test, the ultimate tensile strength of a material can be defined in different ways. Some possible definitions are the onset of plastic yielding (for metals) or the last-ply failure (for laminates). Since it is difficult to detect the first point of damage in laminates, the ultimate tensile strength corresponds to the maximum load a material withstands [6]. Extensive efforts have been made by several investigators to develop a reliable test method to determine the true compressive strength of composite laminates. As a result of these efforts, a number of test methods have evolved and are described in the literature [7-9]. The samples were evaluated by tensile tests according to the ASTM D3039 and compression tests according to ASTM D3410 standards [10, 17, 24].

Hence in this background, characterization of materials is extremely important as it helps to identify parameters that influence the strengths and response of composite materials such as fiber and matrix types and fiber-matrix interface. These data can be used to study the relationship between the tensile/compressive strength, fiber content, orientation, textile preform architecture, type of matrix, mechanical properties and failure modes [12]. Considering the factors affecting the strength and mechanical stresses that can occur in structural polymeric composites, this work was focused to study the effect of fiber content and its orientation on the in-plane tensile, compressive and shear strength properties. 


\section{EXPERIMENTAL PROCEDURES}

\subsection{Materials}

Hybrid composite materials reinforced with Metal Fiber are a new type of laminated composites, which are becoming increasingly popular for various structural applications in the automotive, aerospace and other industrial sectors. The present investigation has been carried out on three materials; isopthalic polyester resin with MEKP catalyst and Cobalt Napthenate accelerator, woven steel and nylon bi-directional fiber mesh. The matrix material was medium viscosity polyester resin, which is cost effective because they require minimal setup costs and the physical properties can be tailored to specific applications. The woven steel and nylon bi-directional fiber mesh were the reinforcements.

\subsection{Specimen Preparation}

The hybrid bi-directional symmetric quasi-isotropic composite specimen was fabricated at room temperature and under constant pressure in the shape of a rectangular plate by hand lay-up technique. Ample precautions were taken to minimize voids in the material and maintain homogeneity. The Specimens were prepared for varied volume fractions of the constituents; matrix material $40 \%$ was constant for all samples, the steel fiber percentage was between 15$45 \%$ in steps of $15 \%$ and the corresponding volume of nylon fiber was estimated. The different bi-directional fiber orientations of $0^{\circ} / 90^{\circ}, 30^{\circ} / 60^{\circ}$ and $\pm 45^{\circ}$ were considered for the preparation of specimen in this study. The specimen preparation was in accordance with ASTM Standards as mentioned earlier.

\subsection{Test Setup}

The tensile and compressive test specimens prepared in accordance with ASTM standards were loaded on a computer controlled Universal Testing Machine. The specimens were clamped in pin-loaded grips and subjected to monotonic uniaxial tension at a displacement rate of 1.27 $\mathrm{mm} / \mathrm{min}$. The tests were closely monitored and conducted at room temperature. Since it is difficult to detect the first point of damage in laminates, the ultimate tensile and compressive strength recorded corresponds to the maximum load the hybrid composite specimen can withstand. The notched tensile strength has been calculated by using the critical load for each specimen.

\section{RESULTS AND DISCUSSION}

Experimentations have been carried out to characterize the candidate composite material under different loading conditions and with various specimen configurations, the analysis of the results and the influence of various parameters on the physical \& mechanical properties are summarized in the following sections. 


\subsection{Physical Properties of Hybrid Laminates}

Density: Density of the laminates was measured according to the ASTM D792 standards [13]. Rectangular samples of size $100 \mathrm{~mm}$ X $20 \mathrm{~mm}$ X $10 \mathrm{~mm}$ were used with thickness and width variations of $\pm 0.25 \mathrm{~mm}$ and $\pm 0.20 \mathrm{~mm}$, respectively. Distilled water at room temperature was used as the immersion fluid and the mass was measured using digital balance with a $10^{-4} \mathrm{~g}$ resolution. To obtain the mean value of density of each group, a total of fifteen specimens such that five from each group were tested.

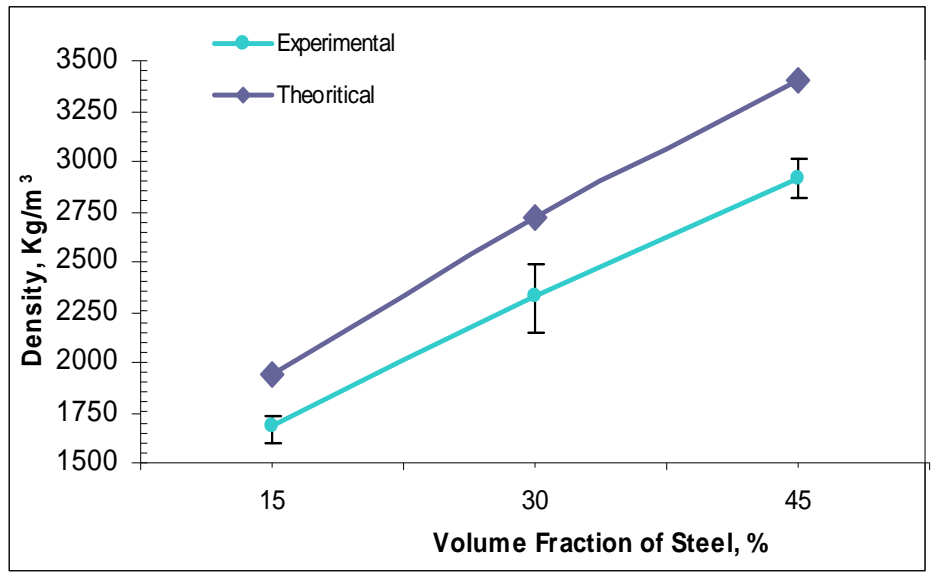

Fig. 1. Density as a Function of Steel Content for $0^{0} / 90^{\circ}$ Fiber Orientation Laminates.

Rule of mixture $[14,15]$ is used to determine theoretical densities of the laminates; the difference in density is shown in Fig. 1. The difference in theoretical and measured densities is mainly due to the presence of micro voids in the composite. Hence it becomes quite essential to measure the percentage of voids in the samples prepared.

There is no significant difference in density of laminates with respect to fiber orientation; this may be attributed to the approximately same warp and fill count. However, the experiments show that the density increase with the increase in steel content, this is because steel being the denser constituent among the selected materials, hence increases the specimen density.

Voids: To analyze the void percentage in the composite laminates; ASTM D2734 standard was used [16]. Up to one percent of voids indicate a good composite, but practical difficulties increase the percentages of voids. Since, the void content of a composite may significantly affect the mechanical properties, as higher percentages of voids usually mean lower fatigue resistance, greater susceptibility to water penetration and weathering lead to increased variation in strength properties. Knowing the densities of the constituents, the volume fractions of fiber, resin, and void were calculated based on two assumptions. The first assumption was that the mass of fiber in the composite was known (i.e., there is no fiber loss during manufacture). The second assumption is that the gas in any voids has the density of air, $1.29 \times 10^{-3} \mathrm{~g} / \mathrm{cm}^{3}$. The results show that void content varies between 6.6 to $7.2 \%$ for laminates with different percentages of reinforcement; details are shown in Table 1. 
Fiber Volume Fraction: ASTM D3171 standards was used to estimate the fiber content of the composite laminates, this method consists of dissolving the resin portion of a weighed composite specimen in a hot digestion medium, i.e., Nitric acid. The residue is filtered, dried, and weighed. The weight percent of fiber can be converted to a volume percent of by using the fiber and resin densities. The volume fraction of laminates was estimated with atleast four samples in each case, results are shown in Table 1.

Table 1. Physical Proportion of the Composite Laminates.

\begin{tabular}{|r|r|r|r|r|r|}
\hline \multirow{2}{*}{ Specimen } & \multicolumn{3}{|c|}{ Volume Fraction, \% } & \multirow{2}{*}{$\begin{array}{c}\text { Void Conten } \\
\text { \% }\end{array}$} & Density, Kg/r \\
\cline { 2 - 4 } & Polyestel & Steel & Nylon & & \\
\hline Sample-1 & $40 \pm 0.4$ & $15 \pm 1.7$ & $45 \pm 1.1$ & 6.64 & 1682 \\
\hline Sample-2 & $40 \pm 0.6$ & $30 \pm 1.2$ & $30 \pm 1.0$ & 7.16 & 2330 \\
\hline Sample-3 & $40 \pm 0.9$ & $45 \pm 1.1$ & $15 \pm 0.9$ & 7.11 & 2916 \\
\hline
\end{tabular}

\subsection{Mechanical Properties of Hybrid Laminates}

The primary purpose of any material characterization is to investigate its behavior under different mechanical loads. The results of the experimentation on the steel reinforced composite material under different loading conditions and for various specimen configurations are discussed in the following sections.

\subsection{Tensile Strength}

ASTM D3039 [17] standards were used to investigate tensile behavior of hybrid composite laminates. The rectangular specimen with dimensions $250 \mathrm{~mm}$ of length X $25.4 \mathrm{~mm}$ of width X $4 \mathrm{~mm}$ of thickness were cut from the planar of polymeric composites. For the in-plane properties of prepared laminates, end-tabs of were bonded; the very purpose of using end-tabs is to provide proper gripping and to ensure failure within the gauge length. Rectangular specimens are required for the composite material characterization, because the dog-bone type tends to split in the region where the width changes. The grips of tension test frame introduce large stress concentration in the specimen, to minimize this effect; tabs with tapered ends were bonded on each side of the specimen. The test ready laminates were subjected to tensile loads on a computer controlled Universal Testing Machine and the tests were performed at a constant crosshead speed of $1.27 \mathrm{~mm} / \mathrm{min}$. In this work the tensile strength is defined as the ultimate strength at which the complete fracture of the specimen occurs and the corresponding load is the critical load or the maximum load a material can with stand. For laminates, this definition corresponds to the lastply failure [18]. The tests were closely monitored and conducted at room temperature and the effects of various parameters are as follows. 
Effect of Fiber Content and Orientation: The effect of fiber content and fiber orientation on tensile strength is analyzed for different specimen configurations. The tensile specimen prepared to suit ASTM standards was subjected to tensile load and the test results are shown in Fig. 2 (a). The experimental results clearly indicate that the trend of increase in tensile strength for increased percentage of steel content, this is evident since the mechanical properties of the steel fibers are superior to those of the nylon and polyester matrix. At the same time the tensile strength of the composite is influenced by the strength and modulus of fibers [19]. At the same time the displacement due to tensile loading is marginal for laminates with higher percentage of steel content, whereas it is considerably less for laminates with steel percentage less than $30 \%$. These variations can be notified that the evolution of the composite displacement at break with the fibers filling ratio is very little because the displacement at break of the fibers and the resin are too close. The increase in steel fiber content at the cost of nylon fiber will certainly increase the tensile strength but the specimen will fail due to the effect of delamination. This is mainly due to the reason that the steel and polyester form poor interface and hence delamination will be more in the laminates with higher steel percentage.

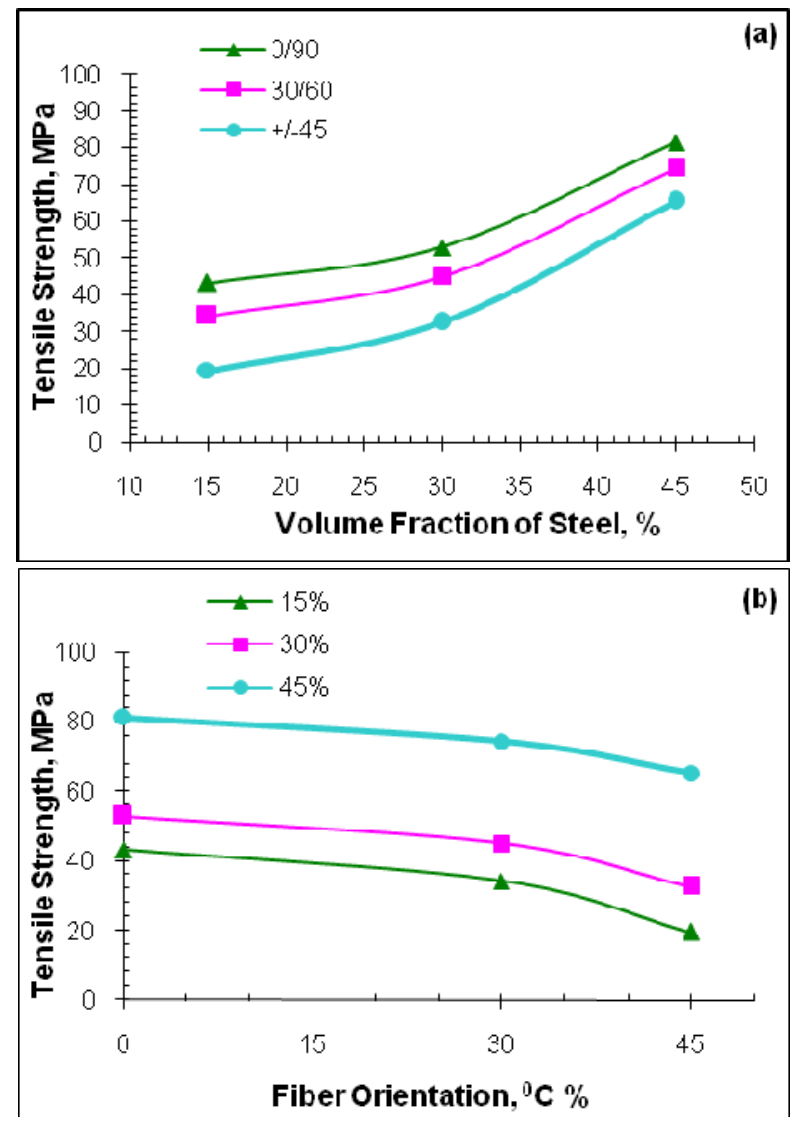

Fig. 2. Influence of steel fiber content on the tensile strength of hybrid composites.

Normally, the composites are designed to load in the direction of the reinforcements. However, in the cases where the load direction is off axis and not parallel to the fibers, it becomes important to investigate the laminate mechanical behavior. The authors at reference $[18,20]$ have 
shown that the composite laminates with $0 / 90^{\circ}$ and $\pm 45^{\circ}$ orientations results in highest and lowest tensile strengths respectively. Hence, to investigate the effect of fiber orientation, three different orientations $0 / 90^{\circ}, 30 / 60^{\circ}$ and $\pm 45^{\circ}$ were selected in this study. Specimens with different fiber orientations were prepared with the same process as described before to suit ASTM D3039 standards [21]. For each fiber orientations, three fiber volume fractions were tested; the influence of fiber orientation can be seen from the Fig. 2 (b).

The experimental results show that the tensile strengths are affected by the fiber orientation significantly. The tensile strength is superior in case of $0^{0} / 90^{0}$ oriented specimens as compared to specimens with $30 / 60^{\circ}$ and $\pm 45^{\circ}$ orientations. This is attributed to the reason that in case of $0^{0} / 90^{\circ}$ orientation the external tensile load is equally distributed on all the fibers and transmitted along the axis of the fibers. Whereas in case of other fiber orientations, fiber axes is non-parallel to load axis, resulting in off axis pulling of fibers and increased stress concentration causing the earlier failure of laminates. Even in case of $30 / 60^{\circ}$ and $\pm 45^{\circ}$ orientations, the trend of increased tensile strength for increase in steel content is true, but it can be clearly observed that the margin of increase is comparatively less. The displacement due to tensile loads again follow the same trend of increased displacement for increase in nylon percentage, this is mainly due to greater extensibility of nylon fibers than other constituent materials [22,23]. But on comparison it is found that the displacement in case of laminates with $\pm 45^{\circ}$ fiber orientation is large compared to laminates with $0 / 90^{\circ}$ and $30 / 60$ orientations, this is due to off axis loading and significant fiber pull out before fracture.

\subsection{Compressive Behavior of Hybrid Composite Laminates}

ASTM D3410 [24] standard was adopted for the study of compressive behavior; the rectangular specimens with $6 \mathrm{~mm}$ thickness were cut to suit required dimensions from the polymeric composite laminate. The Rectangular specimens were tested in a universal testing machine at a constant cross-speed. To minimize the effect of stress concentration, tabs with tapered ends were bonded on each side of the specimen. All the specimens were tested at room temperature. This test is important because it helps to identify parameters that influence the compressive response of composite materials, as fiber and matrix types and fiber-matrix interface. Following discussion outlines the effects of various parameters on compressive strength.

Effect of Fiber Content and Orientation: The results of the compression test to analyze the effect of fiber content and fiber orientation on compressive strength are as shown in Fig. 3. It is quite evident from the results that the compressive strength is superior for $0 / 90^{\circ}$ bidirectional fiber orientation, which is due to reason that the longitudinal fibers directly absorb, transfer and distribute the load uniformly throughout the cross-section. Whereas in case of other fiber orientations, the compressive strength is comparatively lesser, this difference in the load bearing capacity of composites is due to the fact that the fibers start slipping as they are subjected to the load. From the Fig. 3 it is also evident that as steel fiber percentage increases, compressive strength will also increase and it is true upto $30 \%$ of steel content. The change in compressive strength is quite marginal from $30-45 \%$ of steel content; this may be due to that as steel 
percentage increases, the laminates experiences poor interfacial bonding and hence resulting into large delamination and failure of the laminates.

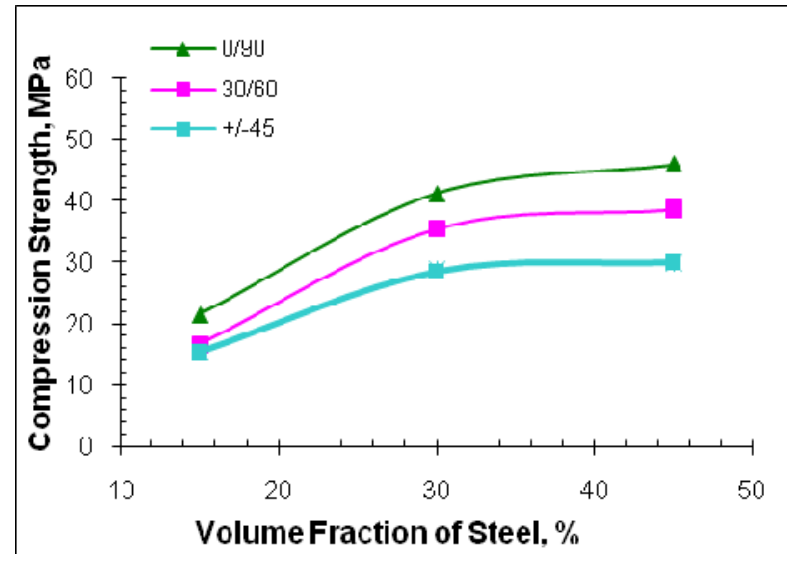

Fig. 3. Influence of Fiber Content and Orientation on the Compressive strength.

\subsection{In-Plane Shear Properties of Laminates}

To determine the in-plane shear properties of the laminates, off-axis tensile tests were carried in a universal testing machine. The specimens prepared from the laminate with an off-axis angle of $45^{\circ}$ such that the fiber orientation is $\pm 45^{\circ}$. The specimen dimensions and test setup is in accordance with ASTM D3518 standards [25]. For gripping and uniform load transfer the laminates were bonded end tabs. Testing conditions and rate of loading was same as that for tension test. This test method involves the measure of the axial load applied to a $\pm 45^{\circ}$ symmetric laminate and from these experimental data the in-plane shear stress referred to the material principal coordinate system, can be obtained as proposed by Rosen [26]. The experimental results of the In-plane shear stress are shown in Fig. 4.

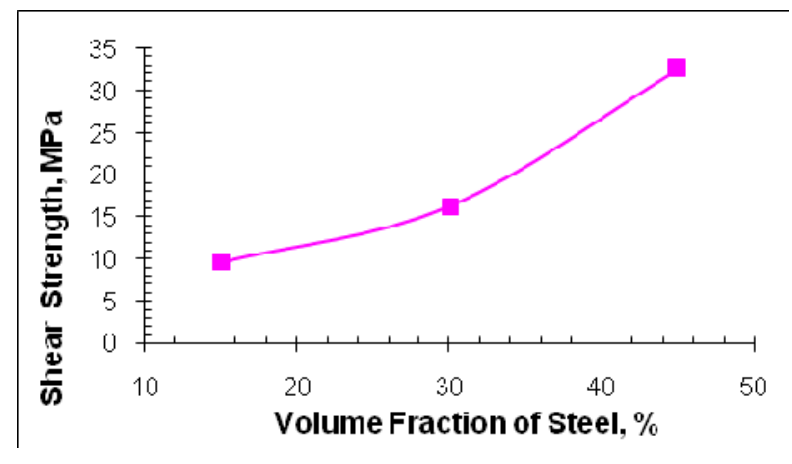

Fig. 4. In-Plane Shear Stress of laminates for various steel percentages.

As expected, the laminate with the highest percent of steel has the largest tensile strength of 65.3 $\mathrm{MPa}$ and its respective shear stress with $32.65 \mathrm{MPa}$. The margin of increase in shear stress is 
quite meager for considerable increase in steel content, this is mainly due to the reason that the shear stress is not only dependent on fiber strength but also on the contact areas [27]. Since in this work the contact area is more or less same for all the specimen combinations, hence the variation in shear stress is mainly attributed to the steel percentage and not to the contact area. The experimental results show that shear stress ranges between $\approx 10$ to $33 \mathrm{MPa}$ for variation in percentage of steel content between 15 to $45 \%$.

\section{CONCLUSIONS}

The experimental investigations used for the analysis of in plane tensile and compressive behavior of hybrid composite laminates leads to the following conclusions:

1. The laminated specimens with higher percentage of steel sustain greater loads irrespective of fiber orientations.

2. Further the specimens sustain greater loads in $0 / 90^{\circ}$ specimens than in other orientations thus can be stated that fiber orientation is a significant factor.

3. Also the change in compressive strength is quite marginal from $30-45 \%$ of steel content due to poor interfacial bonding resulting into large delamination and failure of the laminates.

4. The increase in shear stress is not entirely steel dependent due to that the shear stress is not only dependent on fiber strength but also on the interface between fiber and matrix material.

\section{REFERENCES}

1. S.M.R. Khalili, R.K. Mittal, S. Gharibi Kalibar, "A study of the mechanical properties of steel/aluminium/GRP laminates", Journal of Materials Science and Engineering, A 412,pp.137-140, 2005.

2. Ding YQ, Yan Y, McIlhagger R. Effect of impact and fatique loads on the strength of plain weave carbon-epoxy composites, Journal of Materials Processing Technology. 1995; 55:5862.

3. Gao SL, Kim JK. Cooling rate influences in carbon fiber/PEEK composites. Part III: impact damage performance. Composites: Part A. 2001;32:775-85.

4. Yail J. Kim, Amir Fam, Andrew Kong, and Mark F. Green, "Flexural Strengthening of RC Beams using Steel Reinforced Polymer (SRP) Composites," Synopsis, 2005.

5. Kim J, Shioya M, Kobayashi H, Kaneko J, Kido M. Mechanical properties of woven laminates and felt composites using carbon fibers. Part 1: in-plane properties. Composites Science and Technology. 2004;64:2221-29.

6. B.Gommers, I.Verpoest and P.Van Houtte, "Determination of the Mechanical Properties of Composite Materials by Tensile Tests," J.of Composite Materials, Vol.32, pp. 102-122, 1998. 
7. Berg.J.S and D.F.Adams, "An Evaluation of Composite Material Compression Test Methods,” J. of Composites Technology, Vol.11, No.2, pp.41-46, 1989.

8. Asit.N.R. , "Compression Testing of Homogeneous Materials and Composites,"ASTM STP 808, R.Chait and R.Papirno, eds., Philadelphia:American Society for Testing and Materials, pp. 175-186,1983.

9. KimR.Y. And S.W.Tsai, “A Compressive Test Method for Ring Specimens," Int. SAMPE Symp., pp34-53,1981.

10. ASTM Standards, "ASTM D3039: Standard Test Method for Tensile Properties of Polymer Matrix Composite Materials,” ASTM, West Conshohohoken, PA, 1995, pp. 99-109.

11. Ran.Y. Kim and Allan S. Crasto, "A Longitudinal Compression Test for Composites Using a Sandwich Specimen,” J.of Composite Materials, Vol.26, pp 1915-1929, 1992.

12. Yang B, Kozey V, Adanur S, Kumar S. Bending, compression, and shear behavior of woven glass fiber- epoxy composites. Composites: Part B. 2000; 31:715-21.

13. ASTM D792 Standard Test Method for Compressive Properties of Unidirectional or Crossply Fiber-Resin Composites. American Society for Testing and Materials; 1987.

14. Fukuda H, Kawata K. Fukugo Zairyo Kenkyu (Comp Mat Struct) 1974;3:21.

15. Krishna K Chawla, Composite Material

16. ASTM D2734 Standard Test Method for Compressive Properties of Unidirectional or Cross-ply Fiber-Resin Composites. American Society for Testing and Materials; 1987.

17. John E. Masters and Marc A. Portanova, Standard Test Methods for Textile Composites, National Aeronautics and Space Administration, Langley Research Center Hampton, Virginia 1996.

18. Nayfeh AH. Fiber Sci Technol 1977;10: 196-209.

19. Van den Heuvel PVD, Peijs T, Young RJ. In: The Sixth Int. Conf. on Comp. Interf.,Israel, May 1996.

20. G. Prodromou and J. Chen. 1997. "On the Relationship Between Shear Angle and Wrinkling of Textile Composite Preforms," Composites Part A, 28: 491-503.

21. Wagner HD, Eitan A. Composite Sci Technol 1993;46:353-6.

22. Hedgepeth JM. NASA TN D-882, 1961.

23. Hedgepeth JM, Van Dyke P. Journal of Composite Materials 1967;1:294.

24. ASTM D3410 Standard Test Method for Compressive Properties of Unidirectional or Cross-ply Fiber-Resin Composites. American Society for Testing and Materials; p.132-139. 1987.

25. ASTM D3518 Standard Test Method for Compressive Properties of Unidirectional or Cross-ply Fiber-Resin Composites. American Society for Testing and Materials; 1987.

26. Morais JL, Moura MS, Xavier J, Marques AT. In-plane mechanical behaviour of a glass/epoxy composite. National Conference at Universidade do Porto. $2^{\circ}$ Encontro da Sociedade Portuguesa de Reologia, SPR, FEUP. 2000: 243-252.

27. Konrad Gliesche, Tamara Hubner, Holger Orawetz. Investigations of in-plane shear properties of $\pm 45^{0}$ carbon/epoxy composites using tensile testing and optical deformation analysis. Composites Sciense and Technology. 2005;65:163-171. 